\title{
Increased ERCP volume improves cholangiogram interpretation: a new performance measure for ERCP training?
}

\author{
Shyam Vedantam ${ }^{1}$, Sunil Amin ${ }^{2}$, Ben Maher ${ }^{3,7}$, Saqib Ahmad ${ }^{4}$, Shanil Kadir ${ }^{5}$, Saad Khalid Niaz ${ }^{6}$, Mark Wright', \\ Nadeem Tehami ${ }^{7}$
}

${ }^{1}$ Department of Medicine, University of Miami, Miami, FL; '2Division of Digestive Health and Liver Diseases, Department of Medicine, University of Miami, Miami, FL, USA; ${ }^{3}$ Department of Interventional Radiology, University Hospital Southampton NHS Foundation Trust, Southampton; ${ }^{4}$ Department of Gastroenterology, Sherwood Forest Hospitals NHS Foundation Trust, Sutton in Ashfield, UK; ${ }^{5}$ Department of Gastroenterology, Liaquat National Hospital and Medical College, Karachi; ${ }^{6}$ Interventional Endoscopy Unit, Surgical Unit 4, Dow University of Health Sciences, Karachi, Pakistan; ${ }^{7}$ Southampton Interventional Endoscopy Unit, University Hospital Southampton NHS Foundation Trust, Southampton, UK

Background/Aims: Cholangiogram interpretation is not used as a key performance indicator (KPI) of endoscopic retrograde cholangiopancreatography (ERCP) training, and national societies recommend different minimum numbers per annum to maintain competence. This study aimed to determine the relationship between correct ERCP cholangiogram interpretation and experience.

Methods: One hundred fifty ERCPists were surveyed to appropriately interpret ERCP cholangiographic findings. There were three groups of 50 participants each: “Trainees," "Consultants group 1" (performed >75 ERCPs per year), and "Consultants group 2" (performed $>100$ ERCPs per year).

Results: Trainees was inferior to Consultants groups 1 and 2 in identifying all findings except choledocholithiasis outside the intrahepatic duct on the initial or completion/occlusion cholangiogram. Consultants group 1 was inferior to Consultants group 2 in identifying Strasberg type A bile leaks (odds ratio [OR], 0.86; 95\% confidence interval [CI], 0.77-0.96), Strasberg type B (OR, 0.84; 95\% CI, 0.74-0.95), and Bismuth type 2 hilar strictures (OR, 0.81; 95\% CI, 0.69-0.95).

Conclusions: This investigation supports the notion that cholangiogram interpretation improves with increased annual ERCP case volumes. Thus, a higher annual volume of procedures performed may improve the ability to correctly interpret particularly difficult findings. Cholangiogram interpretation, in addition to bile duct cannulation, could be considered as another KPI of ERCP training.

Keywords: Cholangiograms; Endoscopic retrograde cholangiopancreatography; Key performance indicators; Training

\section{INTRODUCTION}

Endoscopic retrograde cholangiopancreatography (ERCP)

\section{Received: September 23, 2021 Revised: October 26, 2021}

Accepted: November 8, 2021

Correspondence: Nadeem Tehami

Southampton Interventional Endoscopy Unit, University Hospital Southampton NHS Foundation Trust, Tremona Road, Southampton, SO16 6YD, UK

E-mail: nadeem.tehami@nhs.net

(a) This is an Open Access article distributed under the terms of the Creative Commons Attribution Non-Commercial License (http://creativecommons.org/licenses/by-nc/4.0/) which permits unrestricted non-commercial use, distribution, and reproduction in any medium, provided the original work is properly cited. is a technically challenging gastrointestinal procedure. However, ERCP has become more a therapeutic than diagnostic procedure. ${ }^{1,2}$ The type of intervention required often depends on interpretations of the cholangiograms. Training in ERCP is difficult to obtain during the standard fellowship timeline, which has led to an increase in advanced endoscopy fellowship programs. $^{3}$

The shift in ERCP training has led to the development of guidelines that define competency for this procedure. ${ }^{4-7}$ The American Society of Gastrointestinal Endoscopy (ASGE) recommends 200 ERCPs per trainee, with selective cannulation rates of the common bile duct $>80 \%-90 \%$ in a native papilla as 
a surrogate marker of trainee competence. ${ }^{8}$ Alternatively, the British Society of Gastroenterology (BSG) recommends successful cannulation of the target duct, common bile duct (CBD) stone clearance, and stent/cytology of extrahepatic strictures as key performance indicators (KPIs) and a minimum of 75 procedures per year to maintain competence, although one should aspire to complete more than $100 .{ }^{9}$ Table 1 describes the similarities and differences in the achievement and maintenance guidelines of competence stated by the ASGE, BSG, and European Society for Gastrointestinal Endoscopy (ESGE). ${ }^{9-11}$

After successful cannulation, visualization of the biliary tree and interpretation of the images is a crucial step in ERCP. There is a paucity of data regarding this aspect of the procedure. Moreover, whether this skill develops with increased case volumes has not previously been described. The primary aim of this study was to determine whether variation in the case volume of ERCPs per year correlated with the ability to correctly interpret cholangiograms.

\section{METHODS}

Thirteen cholangiograms performed by experienced ERCP endoscopists were independently reported and verified by a consultant hepatopancreatobiliary (HPB) radiologist. The cholangiograms were presented as static images and classified based on findings as follows: Strasberg type A bile leak $(n=1)$, Strasberg type $\mathrm{B}(n=1)$, Bismuth type 1 hilar stricture $(n=2)$, Bismuth type 2 hilar stricture $(n=1)$, distal CBD stricture $(n=1)$, initial cholangiogram (IC) of choledocholithiasis with large stones, i.e., $>10 \mathrm{~mm}(n=1)$, completion/occlusion cholangiogram (CC) after removal of a large stone $(n=1)$, IC of choledocholithiasis with small stones, i.e., $<10 \mathrm{~mm}(n=1)$, CC after removal of a small stone $(n=1)$, IC of choledocholithiasis with intrahepatic duct calculus ( $n=1)$, CC of choledocholithiasis with intrahepatic duct calculus $(n=1)$, and a normal cholangiogram with a mildly dilated CBD $(n=1)$. These images are presented in Figure 1 . The administered survey was included as Supplementary Figure 1.

Images were digitalized, anonymized, and electronically distributed to more than 200 gastroenterologists throughout the world to limit single institution bias between June 2019 and March 2020. The survey participants were gastroenterologists acknowledged by the study authors and small HPB units to avoid bias. Surgeons and radiologists who performed the ERCPs were excluded from the study. Fifty respondents would allow for satisfactory power and appropriate statistical analysis based on a previous survey study of correct interpretation by surgical trainees of intraoperative cholangiograms in laparoscopic cholecystectomy. ${ }^{12}$ The first 50 respondents who completed the questionnaire from each category were included in data analysis.

The open-ended questionnaire asked participants to correctly identify each cholangiographic finding through a single static image. The questionnaire was sent as a Word document containing a table of 13 images with limited clinical information and a blank space next to each for an interpretation. For the relevant images, the questionnaire clearly stated whether the image was an IC or a CC performed at the end of the procedure. Participants were asked to interpret each cholangiogram. The findings were compared with the consultant radiologist's report and identified as correct or incorrect.

Participants were also asked to state their status as either trainee or independent and report the number of ERCPs they performed per annum. Participants were grouped into three categories: "Trainees" who had performed more than 150 ERCPs independently or with minimal assistance; "Consultants group 1," between 75 and 100 ERCPs per year; and "Consultants group 2," more than 100 ERCPs per year.

Statistical analysis was performed using IBM SPSS ver. 27.0 (IBM Corp., Armonk, NY, USA) with member checking. Fisher exact test was used to identify statistically significant differences between the various groups. Statistical significance was set at $p<0.05$. Mantel-Haenszel odds ratios (ORs) and $95 \%$ confidence intervals (CIs) were also calculated.

\section{Ethical statements}

This international survey was regarded as an educational project, and approval from the Ethics or Health Research Authority was not required.

\section{RESULTS}

There were 50 members in each group (Trainees, Consultants group 1, and Consultants group 2). The survey results indicating the correct identification of the lesion are described in Table 2. Mantel-Haenszel ORs, 95\% CIs, and $p$-values are reported in Table 3.

Trainees were noninferior to consultants regarding stone identification. This included IC choledocholithiasis with large stones $(p=0.056), C C$ choledocholithiasis with large stones $(p=0.117)$, and CC choledocholithiasis with small stones $(p=0.056)$. 
Table 1. Key performance indicators adapted from the ASGE, BSG and ESGE

\begin{tabular}{|c|c|c|c|}
\hline KPI category & ASGE recommendation & BSG recommendation & ESGE recommendation \\
\hline \multicolumn{4}{|l|}{ Preprocedure } \\
\hline $\begin{array}{l}\text { Understanding of indications } \\
\text { and risks for ERCP }\end{array}$ & $\begin{array}{l}\text { - >90\% frequency that ERCP is done } \\
\text { for published indication }\end{array}$ & $\begin{array}{l}\text { - Attachment to at least } 1 \text { ERCP unit } \\
\text { during training } \\
\text { - HPB “orientation" program for inter- } \\
\text { ested trainees }\end{array}$ & $\begin{array}{l}\text { - Adequate antibiotic } \\
\text { prophylaxis before ERCP } \\
(>90 \%)\end{array}$ \\
\hline $\begin{array}{l}\text { Understanding of periprocedur- } \\
\text { al care }\end{array}$ & $\begin{array}{l}\text { - >98\% frequency that appropriate } \\
\text { and adequate informed consent is } \\
\text { achieved } \\
\text { - > } 98 \% \text { frequency that appropriate anti- } \\
\text { biotics administered if indicated }\end{array}$ & $\begin{array}{l}\text { - Participation in multidisciplinary } \\
\text { team at hospital and regular meet- } \\
\text { ings }\end{array}$ & - Not commented on \\
\hline Volume and training & $\begin{array}{l}\text { - >98\% frequency that ERCP is per- } \\
\text { formed by fully trained and creden- } \\
\text { tialed endoscopist } \\
\text { - ERCP volume per year is recorded by } \\
\text { endoscopist }\end{array}$ & - 75-100 ERCPs per year & - Not commented on \\
\hline \multicolumn{4}{|l|}{ Intraprocedure } \\
\hline Deep cannulation success rate & $\begin{array}{l}\text { - >90\%-98\% success in native papillae } \\
\text { without surgically altered anatomy }\end{array}$ & $\begin{array}{l}\text { - }>85 \%-90 \% \text { successful cannulation in } \\
\text { 1st ERCP }\end{array}$ & $\begin{array}{l}\text { - Bile duct cannulation rate } \\
(>90 \%)\end{array}$ \\
\hline Stone clearance & $\begin{array}{l}\text { - > } 90 \% \text { success in CBD stone }<1 \mathrm{~cm} \text { in } \\
\text { normal anatomy }\end{array}$ & $\cdot>75 \%-80 \%$ success & $\begin{array}{l}\text { - Clearance of CBD stones } \\
(>90 \%)\end{array}$ \\
\hline $\begin{array}{l}\text { Stent placement for biliary } \\
\text { obstruction or extrahepatic } \\
\text { stricture }\end{array}$ & $\begin{array}{l}\text { - > } 90 \% \text { success in normal anatomy and } \\
\text { in those whose obstruction is below } \\
\text { the bifurcation }\end{array}$ & $\begin{array}{l}\cdot>80 \%-85 \% \text { stent sited and cytology } \\
\text { or histology taken when appropriate }\end{array}$ & $\begin{array}{l}\text { - Stent placement in case of } \\
\text { biliary obstruction }(>90 \%)\end{array}$ \\
\hline \multicolumn{4}{|l|}{ Postprocedure } \\
\hline Communication & $\begin{array}{l}\text { - > } 98 \% \text { reporting of specific tech- } \\
\text { niques, particular accessories used, } \\
\text { all intended outcomes, reporting of } \\
\text { acute adverse events, and contacting } \\
\text { patients within } 14 \text { days for results of } \\
\text { findings }\end{array}$ & $\begin{array}{l}\text { - Participation in multidisciplinary } \\
\text { team at hospital and regular meet- } \\
\text { ings }\end{array}$ & - Not commented on \\
\hline Complications & $\begin{array}{l}\text { - Not applicable: rate of post-ERCP } \\
\text { pancreatitis (noted as priority indica- } \\
\text { tor, but dependent on type of ERCP } \\
\text { performed) } \\
\text { - }<0.2 \% \text { rate of perforation } \\
\text { - }<1 \% \text { rate of clinically significant } \\
\text { hemorrhage after sphincterotomy or } \\
\text { sphincteroplasty }\end{array}$ & $\begin{array}{l}\text { - }<6 \% \text { complication rate for "level 1" } \\
\text { procedures }\end{array}$ & $\begin{array}{l}\text { - Safety of ERCP (PEP rate } \\
<10 \%)\end{array}$ \\
\hline Training programs & - Not commented on & $\begin{array}{l}\text { - Participation in } 300-400 \text { ERCP pro- } \\
\text { cedures prior to consultant appoint- } \\
\text { ment } \\
\text { - Minimum } 2 \text { qualified trainers per } \\
\text { center both of whom participate in } \\
\text { feedback with trainees } \\
\text { - Weekly multidisciplinary meeting } \\
\text { covering benign and malignant } \\
\text { diseases } \\
\text { - Participation in multidisciplinary } \\
\text { meetings, hepatobiliary clinics, pre-/ } \\
\text { post-procedure care } \\
\text { - Colleagues mentor newly appointed } \\
\text { consultants for first } 2 \text { years and are } \\
\text { available to assist in difficult cases }\end{array}$ & - Not commented on \\
\hline
\end{tabular}

ASGE, American Society of Gastrointestinal Endoscopy; BSG, British Society of Gastroenterology; ESGE, European Society for Gastrointestinal Endoscopy; ERCP, endoscopic retrograde cholangiopancreatography; HPB, hepatopancreatobiliary; CBD, common bile duct; PEP, post-ERCP pancreatitis. 

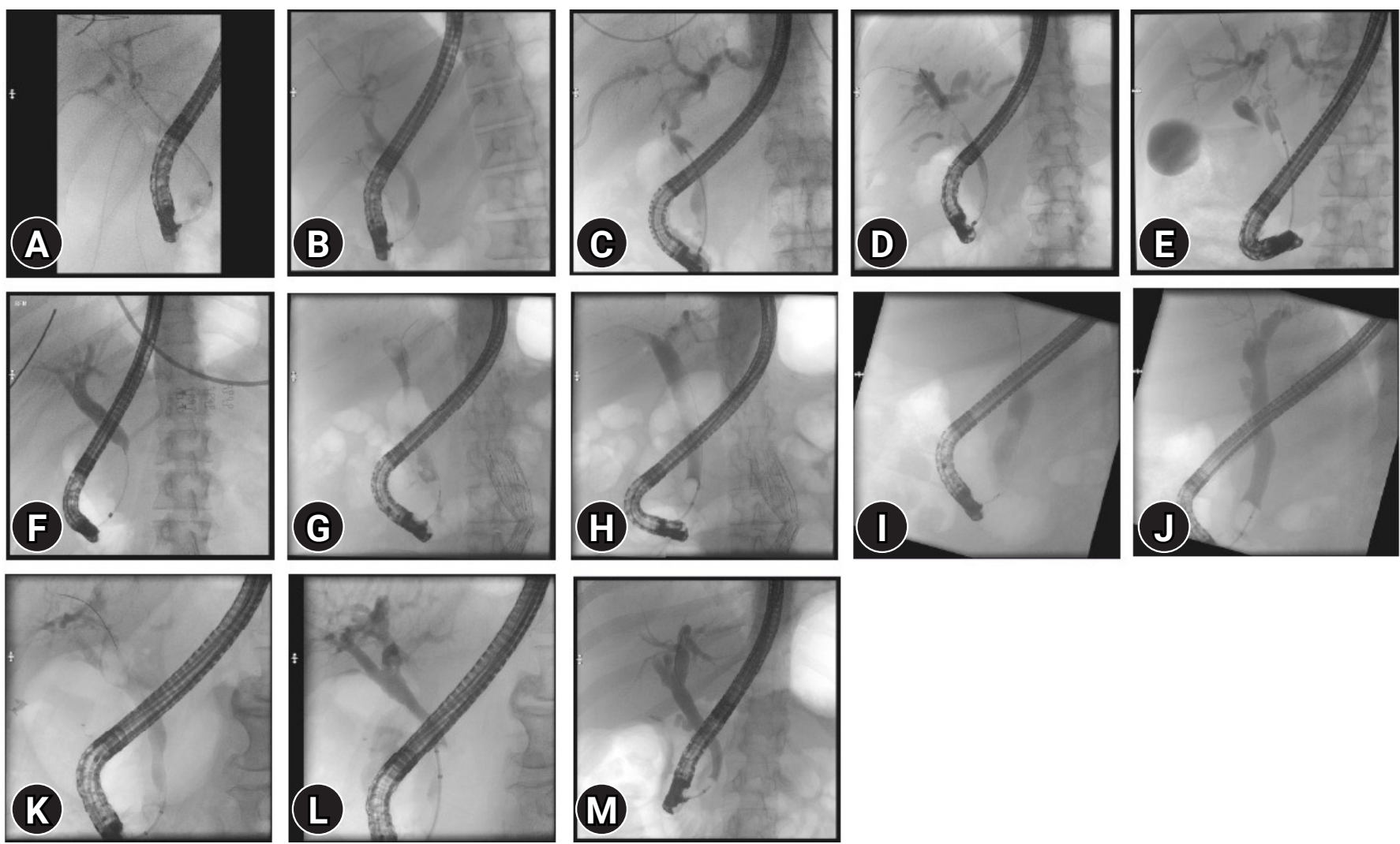

Fig. 1. Cholangiogram images sent in survey. Images were sent in the open-ended questionnaire. (A) Bile leak 1 (Strasberg type A). (B) Bile leak 2 (Strasberg type B). (C) Hilar stricture 1 (Bismuth type 1). (D) Hilar stricture 2 (Bismuth type 1). (E) Hilar stricture 3 (Bismuth type 2 ). (F) Distal CBD stricture. (G) Choledocholithiasis 1 (IC; stone size $>10 \mathrm{~mm}$ ). (H) Choledocholithiasis 1 (CC; stone size $>10 \mathrm{~mm}$ ). (I) Choledocholithiasis 2 (IC; stone size $<10 \mathrm{~mm}$ ). (J) Choledocholithiasis 2 (CC; stone size $<10 \mathrm{~mm}$ ). (K) Choledocholithiasis 3 (IC; IHD calculus). (L) Choledocholithiasis 3 (CC; IHD stone). (M) Normal (mildly dilated CBD). CBD, common bile duct; IC, initial cholangiogram; CC, completion/occlusion cholangiogram; IHD, intrahepatic duct.

Table 2. Accurate interpretation of ERCP cholangiograms: survey results

\begin{tabular}{|c|c|c|c|}
\hline Cholangiogram & $\begin{array}{l}\text { Trainees }(n=50) \\
\text { (number correct) }\end{array}$ & $\begin{array}{c}\text { Consultants group } 1(n=50) \\
\text { (number correct) }\end{array}$ & $\begin{array}{c}\text { Consultants group } 2(n=50) \\
\text { (number correct) }\end{array}$ \\
\hline Bile leak 1 (Strasberg type A) & 37 & 43 & 50 \\
\hline Bile leak 2 (Strasberg type B) & 31 & 42 & 50 \\
\hline Hilar stricture 1 (Bismuth type 1 ) & 30 & 46 & 50 \\
\hline Hilar stricture 2 (Bismuth type 1 ) & 27 & 44 & 49 \\
\hline Hilar stricture 3 (Bismuth type 2) & 25 & 39 & 48 \\
\hline Distal CBD stricture & 34 & 49 & 49 \\
\hline Choledocholithiasis 1 (IC; stone size >10 mm) & 45 & 50 & 50 \\
\hline Choledocholithiasis 1 (CC; stone size $>10 \mathrm{~mm}$ ) & 46 & 50 & 50 \\
\hline Choledocholithiasis 2 (IC; stone size $<10 \mathrm{~mm}$ ) & 44 & 46 & 50 \\
\hline Choledocholithiasis 2 (CC; stone size $<10 \mathrm{~mm}$ ) & 45 & 45 & 50 \\
\hline Choledocholithiasis 3 (IC; IHD calculus) & 29 & 43 & 45 \\
\hline Choledocholithiasis 3 (CC; IHD stone) & 30 & 42 & 47 \\
\hline Normal (mildly dilated CBD) & 41 & 45 & 50 \\
\hline
\end{tabular}

Accurate identification of pathology on ERCP cholangiograms by trainees, graduates, and consultants.

ERCP, endoscopic retrograde cholangiopancreatography; CBD, common bile duct; IC, initial cholangiogram; CC, completion/occlusion cholangiogram; IHD, intrahepatic duct. 
Table 3. Interpretation of ERCP cholangiograms according to the ERCP case volume

\begin{tabular}{|c|c|c|c|c|c|c|}
\hline \multirow[t]{2}{*}{ Cholangiogram } & \multicolumn{2}{|c|}{$\begin{array}{c}\text { Trainees vs. Consultants } \\
\text { group } 1\end{array}$} & \multicolumn{2}{|c|}{$\begin{array}{c}\text { Trainees vs. Consultants } \\
\text { group } 2\end{array}$} & \multicolumn{2}{|c|}{$\begin{array}{l}\text { Consultants group } 1 \text { vs. } \\
\text { Consultants group } 2\end{array}$} \\
\hline & $p$-value & $\mathrm{OR}^{\text {a) }}(95 \% \mathrm{CI})$ & $p$-value & $\mathrm{OR}^{\text {a) }}(95 \% \mathrm{CI})$ & $p$-value & $\mathrm{OR}^{\text {a) }}(95 \% \mathrm{CI})$ \\
\hline Bile leak 1 (Strasberg type A) & 0.211 & & $<0.001$ & $0.740(0.628-0.872)$ & 0.012 & $0.860(0.769-0.962)$ \\
\hline Bile leak 2 (Strasberg type B) & 0.023 & $0.738(0.576-0.946)$ & $<0.001$ & $0.620(.499-0.770)$ & 0.006 & $0.840(0.744-0.948)$ \\
\hline Hilar stricture 1 (Bismuth type 1 ) & $<0.001$ & $0.652(0.513-0.830)$ & $<0.001$ & $0.600(0.478-0.752)$ & 0.117 & \\
\hline Hilar stricture 2 (Bismuth type 1) & $<0.001$ & $0.614(0.466-0.808)$ & $<0.001$ & $0.551(0.425-0.714)$ & 0.112 & \\
\hline Hilar stricture 3 (Bismuth type 2) & 0.006 & $0.641(0.468-0.877)$ & $<0.001$ & $0.521(0.392-0.691)$ & 0.015 & $0.813(0.694-0.951)$ \\
\hline Distal CBD stricture & $<0.001$ & $0.694(0.571-0.843)$ & $<0.001$ & $0.694(0.571-0.843)$ & 1 & \\
\hline Choledocholithiasis 1 (IC; stone size $>10 \mathrm{~mm}$ ) & 0.056 & & 0.056 & & 1 & \\
\hline Choledocholithiasis 1 (CC; stone size $>10 \mathrm{~mm}$ ) & 0.117 & & 0.117 & & 1 & \\
\hline Choledocholithiasis 2 (IC; stone size $<10 \mathrm{~mm}$ ) & 0.741 & & 0.027 & $0.88(0.794-0.975)$ & 0.117 & \\
\hline Choledocholithiasis 2 (CC; stone size $<10 \mathrm{~mm}$ ) & 1 & & 0.056 & & 0.056 & \\
\hline Choledocholithiasis 3 (IC; IHD calculus) & 0.003 & $0.674(0.519-0.876)$ & $<0.001$ & $0.644(0.500-0.830)$ & 0.760 & \\
\hline Choledocholithiasis 3 (CC; IHD stone) & 0.013 & $0.714(0.553-0.923)$ & $<0.001$ & $0.638(0.504-0.809)$ & 0.200 & \\
\hline Normal (mildly dilated CBD) & 0.388 & & 0.003 & $0.820(0.720-0.934)$ & 0.056 & \\
\hline
\end{tabular}

ERCP, endoscopic retrograde cholangiopancreatography; OR, odds ratio; CI, confidence interval; CBD, common bile duct; IC, initial cholangiogram; CC, completion/occlusion cholangiogram; IHD, intrahepatic duct.

${ }^{\text {a) }}$ Mantel-Haenszel odds ratio.

Trainees were inferior to consultants in identifying particularly complex findings, including Strasberg type B ( $p=0.023$, OR 0.738, 95\% CI 0.576-0.946), all hilar strictures (Bismuth type 1: $p<0.001$, OR $0.65,95 \%$ CI 0.51-0.83; a second Bismuth type 1 stricture: $p<0.001$, OR 0.61, 95\% CI 0.47-0.81; and Bismuth type 2: $p=0.006$, OR $0.64,95 \%$ CI $0.47-0.88$ ), and distal CBD strictures ( $p<0.001$, OR $0.69,95 \%$ CI $0.57-0.84)$. Trainees were also inferior to consultants in identifying IC and CC images of choledocholithiasis with intrahepatic duct calculus ( $p=0.003$, OR $0.67,95 \%$ CI $0.52-0.88 ; p=0.013$, OR $0.71,95 \%$ CI $0.55-0.92$, respectively).

Consultants group 1 was inferior to Consultants group 2 regarding several important findings, including the images of Strasberg type A bile leak ( $p=0.012$, OR $0.86,95 \%$ CI $0.77-0.96$ ) and Strasberg type B ( $p=0.006$, OR $0.84,95 \%$ CI 0.74-0.95). Consultants group 1 was also less likely than Consultants group 2 to correctly identify Bismuth type 2 hilar strictures ( $p=0.015$, OR $0.81,95 \%$ CI $0.69-0.95$ ).

\section{DISCUSSION}

Although it is perhaps not surprising that trainees demonstrated less diagnostic ability than independently practicing consultants, it reinforces the importance of cholangiogram interpretation as a key aspect of ERCP learning, which should be assessed.

Regarding the less complex findings (IC of choledocholithiasis with large stones $>10 \mathrm{~mm}$ and CC with small stones
$<10 \mathrm{~mm}$ ), there were no differences between consultants and trainees. Consultants were superior to trainees in identifying particularly complex findings such as Strasberg type B, Bismuth type 1 and 2 hilar strictures, distal CBD strictures, and IC and CC intrahepatic duct calculi. Most interesting was the finding that low volume, independent operators fared worse than did high volume operators in identifying significant pathology despite being "trained." Increased annual case volume correlated with an increased ability to correctly identify Strasberg type A and B bile injuries and Bismuth type 2 hilar strictures.

The relative difficulty of ERCP procedures may vary depending on patient characteristics, biliary anatomy, procedural indication, and intervention. ${ }^{7,13}$ According to one grading system, ERCP procedures for small-to-medium sized biliary stones are less difficult to identify than extrahepatic strictures. ${ }^{714}$ This is congruent with the findings of the present study. Consultants were no better than trainees in identifying most of the stones. But for the majority of other findings, consultants were consistently able to identify more lesion types than trainees were. Those who completed more than 100 procedures per year outperformed those who did not. These findings impugn what determines acceptable competence in comparison to achievable standards.

This study found that consultants in Consultants group 1 were inferior to those in Consultants group 2 in identifying Strasberg type A and B bile injuries and Bismuth type 2 hilar 
strictures. ERCP is an established minimally invasive management option for biliary leaks. ${ }^{15}$ Subsequently, low-grade Bismuth lesions are increasingly under the purview of advanced endoscopists rather than surgeons due to a decreased early complication rate, especially considering surgery in the early postoperative phase is associated with an $80 \%$ complication rate. ${ }^{16,17}$ However, serious adverse events are more likely when therapeutic procedures are performed than when imaging is used alone during ERCP (5\%-10\% vs. $1 \%-3 \%$, respectively). ${ }^{18-20}$ ERCP is associated with recognized risks, including pancreatitis, infection, bleeding, perforation, and anesthesia-related complications. ${ }^{21}$ In addition to these procedure-related complications, studies have shown that complications such as overlooking common duct stones and delaying correct diagnosis may arise from failure to correctly interpret ERCP images. ${ }^{22,23}$ Indeed, this does appear to be a concern for ERCP trainees; a recent survey study reported that only $26 \%$ of trainees received formal training and $97 \%$ expressed a desire for further training. ${ }^{24}$ Therefore, maximizing operator cholangiogram interpretation is imperative to maximize the therapeutic efficacy of ERCP.

A recent systematic review investigated ERCP training and attempted to define what outcomes were being measured or overlooked. ${ }^{6}$ Current literature identifies cannulation rate of a native papilla as the most appropriate measure of ERCP training. However, there was wide variation in other outcomes measured by such studies (for example, the proportion of procedures completed without assistance or successful completion of the therapeutic maneuver). The authors suggested that future studies include six additional independent variables to the reporting standards for ERCP training: previous trainee experience in ERCP, time and method allowed for cannulation attempts, role of supervisor intervention, selective cannulation rate for $\mathrm{CBD}$ in native papilla cases, competence threshold and assessment, and procedure-related complication rate. The authors, although advocating a broader approach to ERCP training, did not mention cholangiogram interpretation as a requisite skill. However, a recent multicenter cohort study included cholangiography skills as 3 of 18 skills for ERCP. ${ }^{4}$ Failure to correctly interpret intraprocedural cholangiograms may lead to incorrect treatment decisions and deleterious patient outcomes. Therefore, this skill should be included in ERCP training and tested in future studies that will be investigating the learning of advanced endoscopists.

This study has several limitations. First, the participants were presented with static images without complete clinical context.
Dynamic images, such as those viewed when performing the procedure, may offer additional diagnostic information. This may be especially true for clinical scenarios such as bile leaks. Additionally, the clinical context (such as brief clinical histories) may impact the pretest probability of a participant's answer, aiding in ascertaining the correct lesion. However, these limiting factors were applicable to all three groups, thus all the participants would have experienced these disadvantages. Nevertheless, consultants with higher per annum volumes outperformed trainees, indicating that even without the entire clinical picture, they were able to outperform their lesser-experienced counterparts. Second, it may have been ideal to test various images of the same condition rather than just one. This could have tested interrater reliability. Third, the survey was open-ended rather than multiple choice; the authors felt that this more accurately represented real clinical circumstances. Varied responses could have introduced subjectivity of the graders, but this was not found to be the case. For example, participants either correctly identified a bile leak or did not. Fourth, the increase in the familywise error rate across the reported statistical analyses was not controlled, which could have increased the chances of a type 1 error. Overall, we consider this research to be relatively preliminary and encourage replication. Furthermore, there appears to be discussions in the literature on whether the Bonferroni correction to address this increased possibility of a type 1 error is necessary because it may increase the chances of type 2 errors. ${ }^{25,26}$ Fifth, participants were separated into three categories based on their ERCP trainee status and number of cases per year. These cutoff values were decided upon based on the current European guidelines, as indicated. Arguably, these are arbitrary numbers and a different approach, such as considering learning curves, years of experience, or previous accreditation/ training through a fellowship program, may have been preferable to categorize the participants. Furthermore, although the nomenclature of Trainees, Consultants group 1, and Consultants group 2 was applied, the duration post-fellowship or prior training experience was not implied. Demographics other than the number of ERCPs performed per year were not collected from the participants, and this may have influenced the results. A future study could investigate how correct lesion identification improves over time with increased ERCP performance by following up with participants. This was, however, beyond the scope of the present study.

This is the first study to investigate correct cholangiogram interpretation in relation to ERCP case volume. The findings of this 
study provide support for the minimum number of ERCP cases required per year per physician, as suggested by the BSG. The results also provide objective evidence for an improved ability to diagnose pathology with increased ERCP performance per year. Our findings are consistent with guidelines from American and European gastroenterology groups. In addition, this survey investigated the ability to correctly identify several clinically important lesions rather than solely assessing a single pathological finding.

The findings of this study may help influence ERCP training and the monitoring of practice quality. The KPI categories and recommendations from different governing societies are presented in Table 1 . Success rates of $>90 \%$ were deemed as KPIs for understanding indications for ERCP, deep cannulation, stone clearance, and stent placement. This score was the highest achieved in Consultants group 2. Therefore, $>90 \%$ correct identification of intraprocedural cholangiogram interpretation may be an additional KPI that should be used during advanced endoscopy training. Although successful cannulation is currently the target marker, the authors argue that this is just the first step in a successful ERCP, and understanding the cholangiogram afterwards is just as important. The percent correct scores found here under the trainees versus consultants in category 1 may help guide in-training exams for fellowship programs to this effect. These scores may provide objective benchmarks for success, especially in identifying different structural lesions, rather than measuring overall subjective progression. Future studies could assess cholangiogram interpretation of trainees during different stages in fellowship programs to ascertain the learning curves and identify barriers to progression and teaching. This is important because trainees are prone to incurring ERCP complications. ${ }^{27,28}$ They could also further investigate how different demographic factors may influence cholangiogram interpretation, such as years of experience versus per annum case volume. Overall, the authors advocate that the BSG KPI minimum of 75 ERCPs per year be increased to 100 ERCPs per year (the BSG "aspirational" goal). Those practitioners who increase their case volume seem to have an improved ability to recognize particularly complex lesions, specifically the type of lesions (Bismuth bile leaks and hilar strictures) increasingly becoming the purview of endoscopists rather than surgeons.

In conclusion, this study demonstrates that operators with higher case volumes perform better at cholangiogram interpretation than those with lower case volumes. Because correct intraprocedural cholangiogram interpretation is imperative for improving ERCP efficacy, it may be included as a KPI of ERCP training and appraisal alongside cannulation and other KPIs.

\section{Supplementary Material}

Supplementary Fig. 1. Please identify what you see in the figure next to each cholangiogram image.

Supplementary materials related to this article can be found online at https://doi.org/10.5946/ce.2021.239.

\section{Conflicts of Interest}

The authors have no potential conflicts of interest.

\section{Funding}

None.

\section{Acknowledgments}

This was an international survey project that would not have been possible without the help of colleagues around the world. Their participation in this project is appreciated.

\section{Author Contributions}

Conceptualization: SAh, SK, SKN, NT; Data curation: SAm, BM, SAh, SK, SKN, MW, NT; Formal analysis: SV, SAm, BM, MW; Investigation: SV, NT; Methodology: SV, NT; Project administration: SAh, SK, SKN, MW, NT; Resources: NT; Software: SV; Supervision: SAm, BM, SAh, SK, SKN, MW, NT; Validation: SAm, BM, MW, NT; Writing-original draft: SV; Writing-review \& editing: all authors.

\section{ORCID}

Shyam Vedantam

Sunil Amin

Ben Maher

Saqib Ahmad

Shanil Kadir

Saad Khalid Niaz

Mark Wright

Nadeem Tehami https://orcid.org/0000-0002-4088-0095 https://orcid.org/0000-0002-3067-4730 https://orcid.org/0000-0003-4049-7229 https://orcid.org/0000-0003-3239-1213 https://orcid.org/0000-0003-3846-660X https://orcid.org/0000-0001-5233-9258 https://orcid.org/0000-0002-3085-5929 https://orcid.org/0000-0003-3042-6574

\section{REFERENCES}

1. Costamagna G, Familiari P, Marchese M, et al. Endoscopic biliopancreatic investigations and therapy. Best Pract Res Clin Gastroenterol 2008;22:865-881.

2. Kapral C, Mühlberger A, Wewalka F, et al. Quality assessment of endoscopic retrograde cholangiopancreatography: results of a running 
nationwide Austrian benchmarking project after 5 years of implementation. Eur J Gastroenterol Hepatol 2012;24:1447-1454.

3. Elta GH, Jorgensen J, Coyle WJ. Training in interventional endoscopy: current and future state. Gastroenterology 2015;148:488-490.

4. Wani S, Keswani RN, Han S, et al. Competence in endoscopic ultrasound and endoscopic retrograde cholangiopancreatography, from training through independent practice. Gastroenterology 2018;155:1483-1494.e7.

5. Shahidi N, Ou G, Telford J, et al. When trainees reach competency in performing ERCP: a systematic review. Gastrointest Endosc 2015; 81:1337-1342.

6. Voiosu T, Bălănescu P, Voiosu A, et al. Measuring trainee competence in performing endoscopic retrograde cholangiopancreatography: a systematic review of the literature. United European Gastroenterol J 2019;7:239-249.

7. Cappell MS, Friedel DM. Stricter national standards are required for credentialing of endoscopic-retrograde-cholangiopancreatography in the United States. World J Gastroenterol 2019;25:3468-3483.

8. ASGE Training Committee, Jorgensen J, Kubiliun N, et al. Endoscopic retrograde cholangiopancreatography (ERCP): core curriculum. Gastrointest Endosc 2016;83:279-289.

9. The British Society of Gastroenterology (BSG). ERCP: the way forward, a standards framework [Internet]. London: BSG; 2013 [cited 2021 Dec 9]. Available from: https://www.bsg.org.uk/wp-content/ uploads/2019/12/ERCP-\%E2\%80\%93-The-Way-Forward-A-Standards-Framework-1.pdf.

10. Adler DG, Lieb JG, Cohen J, et al. Quality indicators for ERCP. Gastrointest Endosc 2015;81:54-66.

11. Domagk D, Oppong KW, Aabakken L, et al. Performance measures for ERCP and endoscopic ultrasound: a European Society of Gastrointestinal Endoscopy (ESGE) quality improvement initiative. Endoscopy 2018;50:1116-1127.

12. Sanjay P, Tagolao S, Dirkzwager I, et al. A survey of the accuracy of interpretation of intraoperative cholangiograms. HPB (Oxford) 2012; 14:673-676.

13. Caglar E, Atasoy D, Tozlu M, et al. Experience of the endoscopists matters in endoscopic retrograde cholangiopancreatography in Billroth II gastrectomy patients. Clin Endosc 2020;53:82-89.

14. Cotton PB. Are low-volume ERCPists a problem in the United States? A plea to examine and improve ERCP practice-NOW. Gastrointest Endosc 2011;74:161-166.

15. Barkun AN, Rezieg M, Mehta SN, et al. Postcholecystectomy biliary leaks in the laparoscopic era: risk factors, presentation, and management. McGill Gallstone Treatment Group. Gastrointest Endosc 1997;45:277-282.

16. Davids PH, Tanka AK, Rauws EA, et al. Benign biliary strictures. Surgery or endoscopy? Ann Surg 1993;217:237-243.

17. Bergman JJ, van den Brink GR, Rauws EA, et al. Treatment of bile duct lesions after laparoscopic cholecystectomy. Gut 1996;38: 141-147.

18. Loperfido S, Angelini G, Benedetti G, et al. Major early complications from diagnostic and therapeutic ERCP: a prospective multicenter study. Gastrointest Endosc 1998;48:1-10.

19. Tanner AR. ERCP: present practice in a single region. Suggested standards for monitoring performance. Eur J Gastroenterol Hepatol 1996;8:145-148

20. Masci E, Toti G, Mariani A, et al. Complications of diagnostic and therapeutic ERCP: a prospective multicenter study. Am J Gastroenterol 2001;96:417-423.

21. Andriulli A, Loperfido S, Napolitano G, et al. Incidence rates of post-ERCP complications: a systematic survey of prospective studies. Am J Gastroenterol 2007;102:1781-1788.

22. Chan CK, Pace RF. Misdiagnosis using endoscopic retrograde cholangiopancreatography in a patient with postcholecystectomy pain. Surg Endosc 1987;1:179-180.

23. Trap R, Adamsen S, Hart-Hansen O, et al. Severe and fatal complications after diagnostic and therapeutic ERCP: a prospective series of claims to insurance covering public hospitals. Endoscopy 1999;31:125-130.

24. Siau K, Webster G, Wright M, et al. Attitudes to radiation safety and cholangiogram interpretation in endoscopic retrograde cholangiopancreatography (ERCP): a UK survey. Frontline Gastroenterol 2020;12:550-556

25. Perneger TV. What's wrong with Bonferroni adjustments. BM] 1998;316:1236-1238.

26. Nakagawa S. A farewell to Bonferroni: the problems of low statistical power and publication bias. Behavioral Ecology 2004;15:1044-1045.

27. Desai R, Patel U, Doshi S, et al. A nationwide assessment of the "July Effect" and predictors of post-endoscopic retrograde cholangiopancreatography sepsis at urban teaching hospitals in the United States. Clin Endosc 2019;52:486-496

28. Lee TY, Nakai Y. Is the July effect real in patients undergoing endoscopic retrograde cholangiopancreatography? Clin Endosc 2019;52:399-400. 